\title{
Rhodium catalysed chemo- and stereoselective arylative and alkenylative cyclisation reactions of unsymmetric diynes containing a terminal alkyne moiety with organoboronic acids $\dagger$
}

\author{
Levent Artok, ${ }^{* a}$ Melih Kuş, ${ }^{a}$ Bağdagül N. Ürer, ${ }^{a}$ Gülşah Türkmen ${ }^{a}$ and Özge Aksın-Artok ${ }^{b}$ \\ Received 22nd December 2009, Accepted 11th February 2010 \\ First published as an Advance Article on the web 1st March 2010 \\ DOI: 10.1039/b926553h
}

Unsymmetric diynes possessing a terminal alkyne moiety reacted with organoboronic acids both chemo- and stereoselectively to afford arylated or alkenylated exocyclic dienes by catalysis from the $\left[\mathrm{Rh}(\mathrm{cod}) \mathrm{OCH}_{3}\right]_{2}$ complex. The use of a polar protic solvent, e.g. $\mathrm{CH}_{3} \mathrm{OH}$ is required for the success of the process under mild conditions.

\section{Introduction}

In 2001, Hayashi et al. reported the first Rh-catalysed cis-1,2addition of arylboronic acids to internal alkynes. ${ }^{1}$ Since then, numerous studies have been performed on rhodium catalysed cascade reactions of alkynes bearing an electrophilic moiety at an appropriate position with organoborons as a strategy for constructing arylative cyclised products, offering sequential formation of multiple $\mathrm{C}-\mathrm{C}$ bonds in one pot., ${ }^{2,3}$

The reaction is generally believed to be initiated via the regioselective 1,2-addition of organorhodium species, generated through transmetalation between organoboron and rhodium(I) ${ }^{4}$ across a carbon-carbon multiple bond. This addition is facilitated through the coordination of the rhodium species across two electrophilic reactive parts of the substrate and hence, requires milder conditions compared to that of simple alkynes. ${ }^{3 g}$ Then, the resulting organorhodium species adds to the other intramolecular group, thus constructing a cyclic product. Interestingly, however, the process has not yet been explored for acceptors with two or more electrophilic functionalities possessing a terminal alkyne site. ${ }^{5}$ This may be due either to the high propensity of terminal alkynes towards oligomerisation reactions or to their lower reactivity. ${ }^{6}$

There is only one example in the literature that demonstrated the results of the rhodium catalysed reactions of 1,5-enynes possessing a terminal alkyne moiety with organoboronic acids, in which the intermolecular carborhodation process proceeded in a geminal fashion through the formation of rhodium vinylidene species to provide 1-substituted cyclopentene products. ${ }^{7}$ However, we have determined in this study that a chemo- and stereoselective arylation or alkenylation of a terminal alkyne is possible without the involvement of vinylidene species provided that the alkynyl

${ }^{a}$ Department of Chemistry, Faculty of Science, Izmir Institute of Technology, Urla, 35430, Izmir, Turkey.E-mail: leventartok@iyte.edu.tr; Fax: (+)90232-7507509

${ }^{b}$ Organic Chemistry II, Dortmund University of Technology, Otto-HahnStrasse 6, D-44227, Dortmund, Germany

$\dagger$ Dedicated to Prof. Masakatsu Nomura on the occasion of his 70th birthday

\$ Electronic supplementary information (ESI) available: Compound characterization data, and ${ }^{1} \mathrm{H}$ and ${ }^{13} \mathrm{C}$ NMR spectra of compounds. See DOI: $10.1039 / \mathrm{b} 926553 \mathrm{~h}$ moiety is tethered to another unsaturated functionality positioned in 1,6- or 1,7-arrangements.

\section{Results and discussion}

Unsymmetric diynes with a terminal alkyne moiety were the substrates mainly employed in this study to verify the relative preference of the carborhodation process between internal and terminal alkyne sites. We initially attempted a reaction with an unsymmetric 1,6-diyne 1a and phenylboronic acid 2a mixture $(1: 1.2)$ in the presence of $[\mathrm{Rh}(\mathrm{cod}) \mathrm{OH}]_{2}(3 \% \mathrm{Rh}, \mathrm{cod}=$ cycloocta1,5-diene $)$ in a dioxane- $\mathrm{H}_{2} \mathrm{O}(40: 1)$ mixture at room temperature, which was derived from the method employed for the arylative cyclisation of internal 1,6-diynes by Murakami et al. (at a Rh concentration of $6 \%$ and with an arylboronic acid to diyne ratio of $3: 1){ }^{3 o}$ Surprisingly, these experimental conditions failed to produce any product and the starting material was recovered (Table 1, entry 1). Diyne 1a was also completely unreactive under the conditions that generated $[\mathrm{Rh}]-\mathrm{OH}$ species in situ from the $[\mathrm{Rh}(\mathrm{cod}) \mathrm{Cl}]_{2}$ complex in tetrahydrofuran (THF), 1,2dimethoxyethane (DME), and dioxane solvents (Table 1, entries 2-4). ${ }^{8}$ Nevertheless, the increase in the amount of added water provided the formation of an arylative exocylic conjugated diene product 3aa, albeit at a low yield (Table 1, entry 5); the application of more forcible reaction conditions $\left(60{ }^{\circ} \mathrm{C}\right.$ and with $\left.6 \% \mathrm{Rh}\right)$ was also unsuccessful, resulting in a complex mixture (Table 1, entry 6).

Gratifyingly, 1a and 2a were effectively coupled in a chemoand stereoselective manner with complete conversion within just $1 \mathrm{~h}$, in the presence of the $\left[\mathrm{Rh}(\mathrm{cod}) \mathrm{OCH}_{3}\right]_{2}$ complex $(3 \% \mathrm{Rh})$, and in a $\mathrm{CH}_{3} \mathrm{OH}-\mathrm{H}_{2} \mathrm{O}(40: 1)$ solvent system, thus providing 3aa in an isolated yield of $73 \%$ (Table 1 , entry 7 ). The aryl group was incorporated exclusively into the terminal alkyne site and the configurations of the exocyclic double bonds were assigned by an NOE study. ${ }^{9,10}$

Also similar results were obtained in a dry $\mathrm{CH}_{3} \mathrm{OH}$ solvent and under conditions when [Rh]- $\mathrm{OCH}_{3}$ was likewise generated in situ by the use of the $[\mathrm{Rh}(\mathrm{cod}) \mathrm{Cl}]_{2}-\mathrm{KOH}$ combination in a $\mathrm{CH}_{3} \mathrm{OH}-$ $\mathrm{H}_{2} \mathrm{O}$ solvent system (Table 1, entries 8 and 9). ${ }^{11}$ The beneficial effect of water became noticeable only when using a lower concentration of the $[\mathrm{Rh}(\operatorname{cod}) \mathrm{Cl}]_{2}(0.8 \% \mathrm{Rh})$ complex, though lower yields were 
Table 1 Rhodium-catalysed reaction of diethyl 2-(but-2-ynyl)-2-(prop-2-ynyl)malonate (1a) with phenylboronic acid (2a): optimisation study
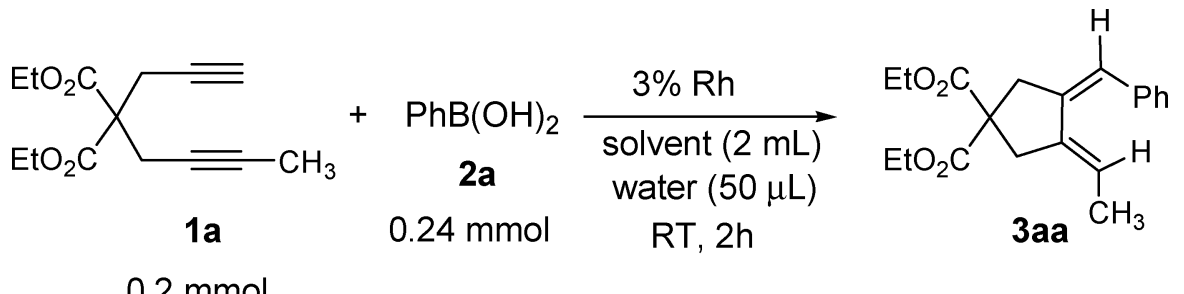

$0.2 \mathrm{mmol}$

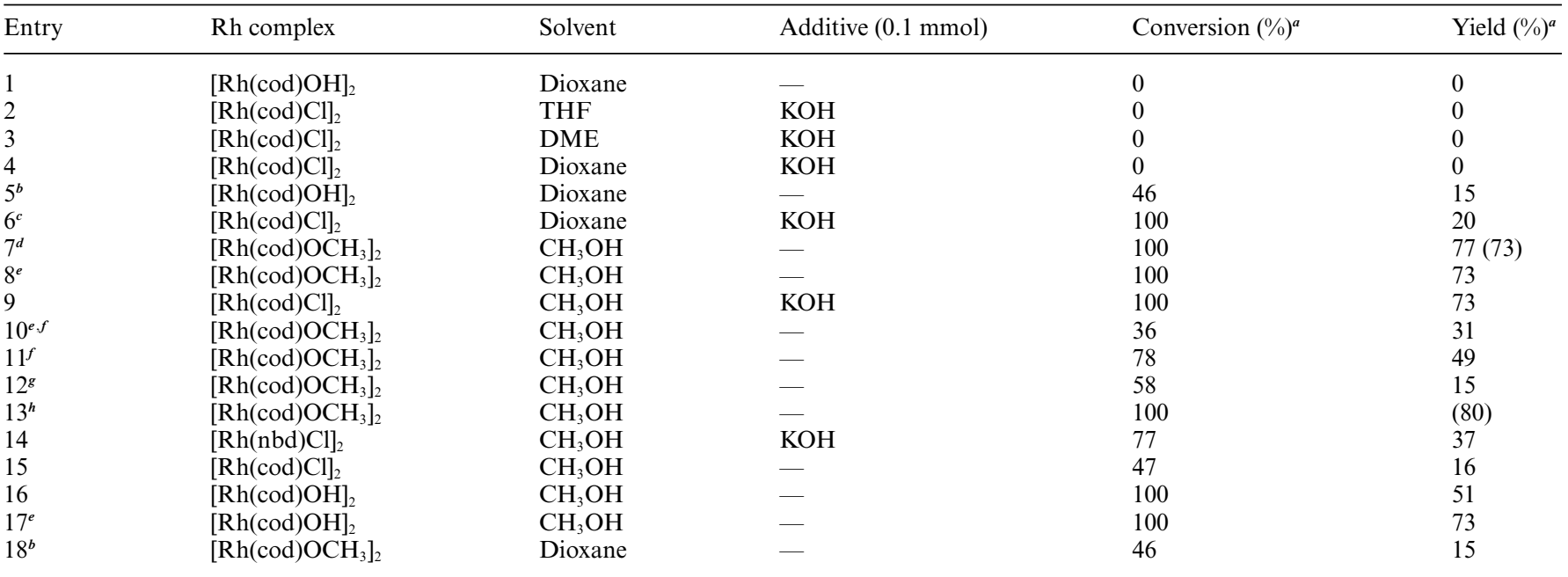

${ }^{a}$ Calculated by ${ }^{1} \mathrm{H}$ NMR relative to an internal standard (1,3,5-trimethoxybenzene). Isolated yields are given in parentheses. ${ }^{b}$ Contained $0.2 \mathrm{~mL}$ of water. Reaction time is $17 \mathrm{~h} .{ }^{c}$ Contained $6 \%$ of $\mathrm{Rh}$ and $0.2 \mathrm{~mL}$ of water and performed at $60{ }^{\circ} \mathrm{C}$ for $4 \mathrm{~h} .{ }^{d}$ Reaction time is $1 \mathrm{~h} .{ }^{e}$ Without added water. ${ }^{f}$ Contained $0.8 \%$ of $\mathrm{Rh} .{ }^{g}$ Performed at $10{ }^{\circ} \mathrm{C}$ for $14 \mathrm{~h} .{ }^{h}$ Contained $0.6 \mathrm{mmol}$ of $\mathrm{PhB}(\mathrm{OH})_{2}$.

obtained in both cases (Table 1 , entries 10 and 11). Lowering the reaction temperature to $10{ }^{\circ} \mathrm{C}$ greatly reduced the activity of the $\left[\mathrm{Rh}(\mathrm{cod}) \mathrm{OCH}_{3}\right]_{2}-\mathrm{CH}_{3} \mathrm{OH}$ system (Table 1, entry 12). Although a somewhat higher yield for 3aa $(80 \%)$ was possible with the use of three equivalents of $\mathbf{2 a}$ (Table 1 , entry 13), a preferred ratio of $1: 1.2(1: 2)$ was chosen for the rest of the study in order to limit the use of the expensive arylboronic acid reagent.

Interestingly, the analogous $[\mathrm{Rh}(\mathrm{nbd}) \mathrm{Cl}]_{2}$ complex $(\mathrm{nbd}=$ norbornadiene) proved less effective in basic $\mathrm{CH}_{3} \mathrm{OH}$ solution (Table 1, entry 14), indicating that cod is a better ligand partner than nbd for the catalytic activity of the rhodium species in this reaction.

To better comprehend whether the superior activity of the $\left[\mathrm{Rh}(\mathrm{cod}) \mathrm{OCH}_{3}\right]_{2}-\mathrm{CH}_{3} \mathrm{OH}$ system compared to the $[\mathrm{Rh}(\mathrm{cod}) \mathrm{OH}]_{2}$-dioxane system is due to the different anionic ligand partner type on the rhodium complex or to the effect of the solvent type, several arylative cyclisation experiments were also carried out in methanol with $[\mathrm{Rh}(\mathrm{cod}) \mathrm{Cl}]_{2}$ and $[\mathrm{Rh}(\mathrm{cod}) \mathrm{OH}]_{2}$ complexes, and in dioxane with $\left[\mathrm{Rh}(\mathrm{cod}) \mathrm{OCH}_{3}\right]_{2}$. The $[\mathrm{Rh}(\operatorname{cod}) \mathrm{Cl}]_{2}$ complex displayed only slight activity in the $\mathrm{CH}_{3} \mathrm{OH}-\mathrm{H}_{2} \mathrm{O}$ solvent in the absence of a base, producing 3aa in 16\% yield (Table 1, entry 15). On the other hand, conversion of diyne 1a was complete in the presence of the $[\mathrm{Rh}(\mathrm{cod}) \mathrm{OH}]_{2}$ complex under identical conditions, giving rise to $\mathbf{3 a a}$ in 51 and $73 \%$ yields in the moist and dry methanol solvents, respectively (Table 1, entries 16 and 17), contrasting with the performance of the complex $\left[\mathrm{Rh}(\mathrm{cod}) \mathrm{OCH}_{3}\right]_{2}$ in these solvent systems. However, the fact that the $\left[\mathrm{Rh}(\mathrm{cod}) \mathrm{OCH}_{3}\right]_{2}$ complex also showed low activity in a dioxane solvent indicates that the reaction can proceed effectively only in a polar protic solvent, such as $\mathrm{CH}_{3} \mathrm{OH}$ (Table 1, entry 18).

Fig. 1 shows the ${ }^{1} \mathrm{H}$ NMR spectra of $\mathrm{CDCl}_{3}$ solutions of the rhodium complexes $[\mathrm{Rh}(\mathrm{cod}) \mathrm{Cl}]_{2}$ and $[\mathrm{Rh}(\mathrm{cod}) \mathrm{OH}]_{2}(\approx 0.031$ $\mathrm{M})$ observed in the presence of $\approx 0.31 \mathrm{M}$ concentration of $\mathrm{CH}_{3} \mathrm{OH}$. The $[\mathrm{Rh}(\mathrm{cod}) \mathrm{Cl}]_{2}$ complex seemed stable during neutral $\mathrm{CH}_{3} \mathrm{OH}$ treatment as no structural changes could be assigned by the ${ }^{1} \mathrm{H}$ NMR study. Nevertheless, the presence of a signal at $2.67 \mathrm{ppm}$, which is assigned to the rhodium attached methoxo ligand, ${ }^{11}$ within the ${ }^{1} \mathrm{H}$ NMR spectrum of $[\mathrm{Rh}(\mathrm{cod}) \mathrm{OH}]_{2}-\mathrm{CH}_{3} \mathrm{OH}$ combination indicates that a partial conversion of $[\mathrm{Rh}(\mathrm{cod}) \mathrm{OH}]_{2}$ to $\left[\mathrm{Rh}(\mathrm{cod}) \mathrm{OCH}_{3}\right]_{2}$ complex can take place in the presence of $\mathrm{CH}_{3} \mathrm{OH}$ even in the absence of a base.

The rhodium complex $\left[\mathrm{Rh}(\mathrm{cod}) \mathrm{OCH}_{3}\right]_{2}$ was treated in a dioxane- $\mathrm{H}_{2} \mathrm{O}(40: 1)$ mixture under an $\mathrm{Ar}$ atmosphere in the absence of any other reagent. The NMR analyses (in $\mathrm{CDCl}_{3}$ ) of the rhodium sample recovered from the dioxane- $\mathrm{H}_{2} \mathrm{O}$ solution by evaporation demonstrated the presence of the $[\mathrm{Rh}(\mathrm{cod}) \mathrm{OH}]_{2}$ complex only. These results suggest that the effective exchange of anionic ligands with the alkoxo ligand is needed to render higher activity to the rhodium complex, while the possible complexation of the $\mathrm{CH}_{3} \mathrm{OH}$ solvent with a metal centre and/or a strong hydrogen bond formation between solvent and $-\mathrm{OCH}_{3}$ and $-\mathrm{OH}$ ligands, as shown previously, may also affect catalytic activity of rhodium at various stages of the reaction cycle. ${ }^{6 a, 12}$

The $\left[\mathrm{Rh}(\mathrm{cod}) \mathrm{OCH}_{3}\right]_{2}-\mathrm{CH}_{3} \mathrm{OH}$ combination also proved relatively more amenable to the arylative cyclisation of a methyl substituted internal symmetric diyne $\mathbf{4}$; the reaction of $\mathbf{4}$ with 
Table 2 Rhodium catalysed reaction of diethyl 2,2-di(but-2-ynyl)malonate (4) with phenylboronic acid (2a)
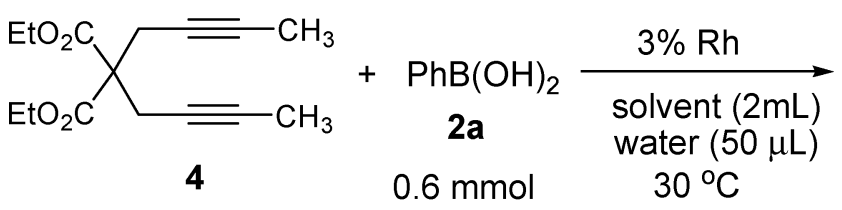<smiles>C/C=C1\CC(C(=O)OCC)(C(=O)OCC)C\C1=C(\C)c1ccccc1</smiles>

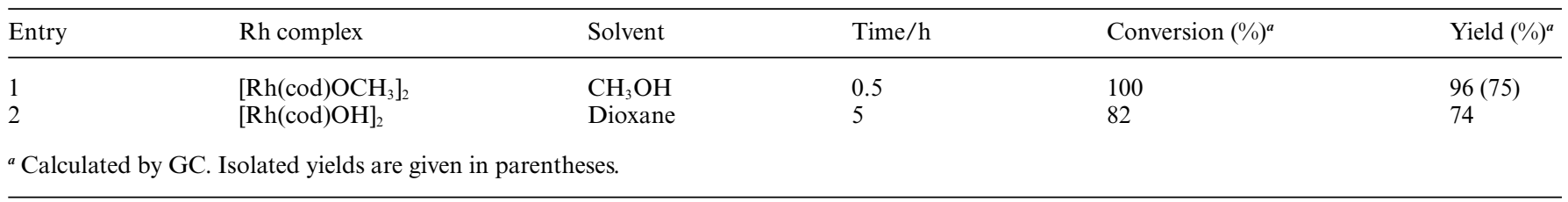

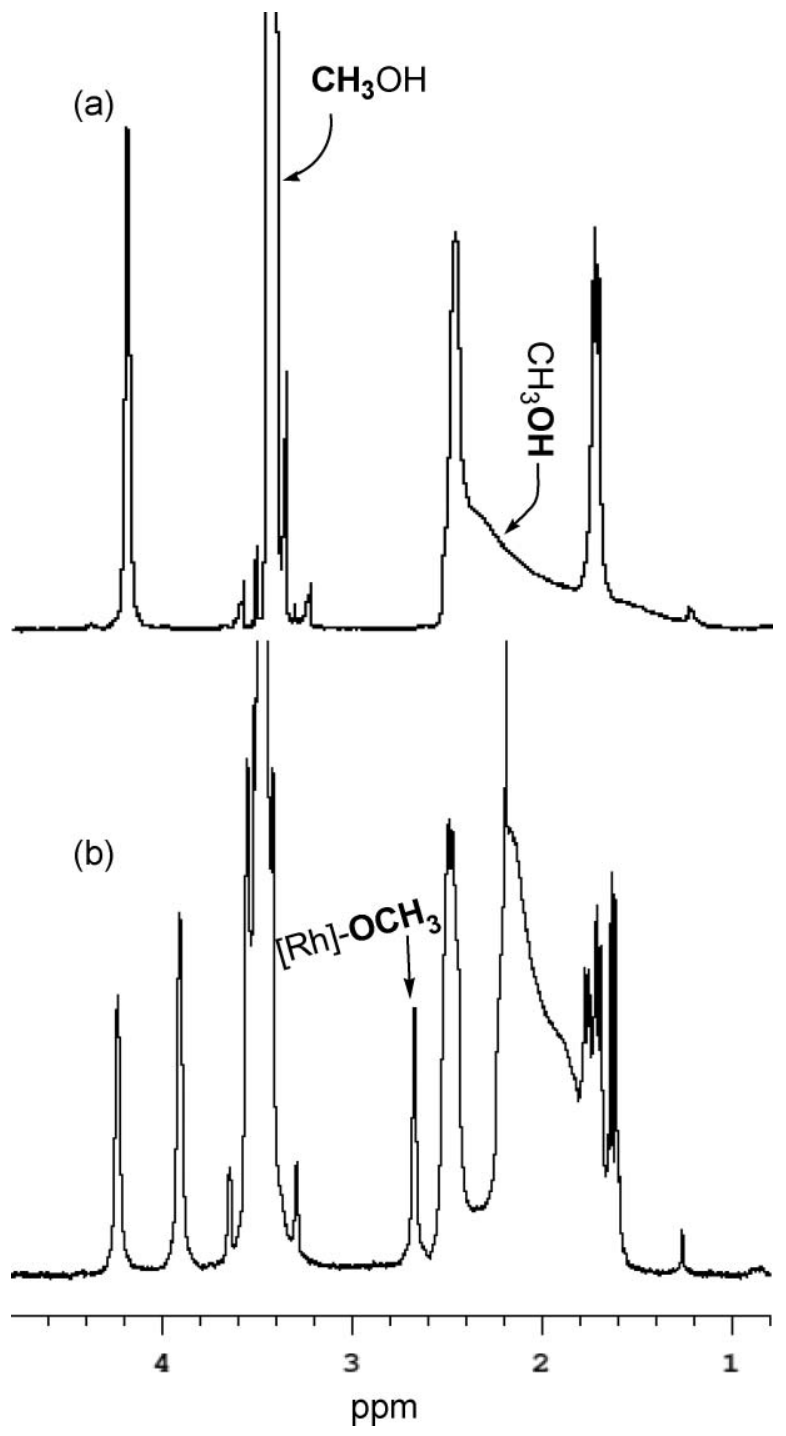

Fig. $1{ }^{1} \mathrm{H}$ NMR spectra of $[\mathrm{Rh}(\operatorname{cod}) \mathrm{Cl}]_{2}$ (a) and $[\mathrm{Rh}(\operatorname{cod}) \mathrm{OH}]_{2}$ (b) observed in the presence of methanol in $\mathrm{CDCl}_{3}(\mathrm{Rh}$ complex $=0.031 \mathrm{M}$, $\left.\mathrm{CH}_{3} \mathrm{OH}=0.31 \mathrm{M}\right)$.

three equivalents of $\mathbf{2 a}$ proceeded to completion at $30^{\circ} \mathrm{C}$ in $30 \mathrm{~min}$ to afford a high yield of the corresponding product 5a with this combination (Table 2, entry 1), whereas the conversion of the substrate 4 was incomplete when the reaction was performed in dioxane in the presence of the $[\mathrm{Rh}(\mathrm{cod}) \mathrm{OH}]_{2}$ complex (Table 2, entry 2). However, it would also be interesting to note that the conversion of substrate 4 was less than $10 \%$ when reacted with 1.2 equivalents of $\mathbf{2 a}$ in dioxane, in the presence of $[\mathrm{Rh}(\mathrm{cod}) \mathrm{OH}]_{2}$, and at room temperature.

The optimal method that is established for the arylative cyclisation of diynes in this study, which made use of the complex $\left[\mathrm{Rh}(\mathrm{cod}) \mathrm{OCH}_{3}\right]_{2}(3 \% \mathrm{Rh})$ and $\mathrm{CH}_{3} \mathrm{OH}-\mathrm{H}_{2} \mathrm{O}$ solvent system, also operated well with an enyne reagent (6) which possesses an unsubstituted alkyne functionality, affording the cyclative product $7 \mathbf{a}$ in an isolated yield of $80 \%$ (Table 3 , entry 1 ). In contrast, the use of the $[\mathrm{Rh}(\mathrm{cod}) \mathrm{OH}]_{2}$-dioxane- $\mathrm{H}_{2} \mathrm{O}$ system was highly detrimental for the conversion of $\mathbf{6}$ under analogous reaction conditions (Table 3, entry 2). Nevertheless, following Hayashi's experimental conditions, which involved the use of a higher $\mathrm{Rh}$ concentration $(6 \%)$ and a higher temperature $\left(60{ }^{\circ} \mathrm{C}\right)$ while generating $[\mathrm{Rh}]-\mathrm{OH}$ in situ, led to the formation of $7 \mathbf{a}$ in $69 \%$ yield. $^{3 e}$

Having determined the effective conditions, an array of substituted boronic acids was then subjected to the reactions with diyne 1a. The reaction tolerated both electron withdrawing and donating groups on the $m$ - and $p$-positions $(\mathbf{2} \mathbf{b}-\mathbf{g})$, and $o$-tolylboronic acid (2h), giving rise to good yields of the corresponding products 3abah (61-74\%, Table 4, entries 1-7). An electron-poor disubstituted phenylboronic acid $\mathbf{2} \mathbf{i}$, a heterocyclic boronic acid $\mathbf{2} \mathbf{j}$, and an alkenylboronic acid $\mathbf{2 k}$ were all suitable components for the reaction, yielding related cyclised products 3ai-ak in the range of $68-74 \%$ yield (Table 4 , entries $8-10$ ).

The scope of unsymmetric diyne substrates was also surveyed with different tether types and substituent groups on one of the alkyne termini. The unsymmetric 1,6-diynes having a malonatebased tether with $-\mathrm{C}_{2} \mathrm{H}_{5}$ and $-\mathrm{Si}\left(\mathrm{CH}_{3}\right)_{3}$ substituents at one of the alkynyl groups (1b,c), and primary and tertiary 1,6-diynols (1d,e) (Table 5, entries 1-4) were all applicable substrates that converted in a chemo- and stereoselective manner to the corresponding 1,2-dialkylidenecyclopentane products in good yields. It must be noted that in a previous report, rhodium-catalysed arylative cyclisation reactions of internal unsymmetrical 1,6-diynes with $\mathrm{CH}_{3} / \mathrm{CH}_{2} \mathrm{OR}$ substituents worked with opposite chemoselectivity and involved an arylation step primarily on the $\mathrm{CH}_{2} \mathrm{OR}$ substituted site, which is probably directed by the coordination of the $\mathrm{Rh}$ species with the propargylic oxygen atom..$^{3 o}$ In contrast, rhodoarylation is under selective steric control for the reactions of 
Table 3 Rhodium catalysed reaction of (E)-4,4-diethyl 1-methyl hept-1-en-6-yne-1,4,4-tricarboxylate (6) with phenylboronic acid (2a)
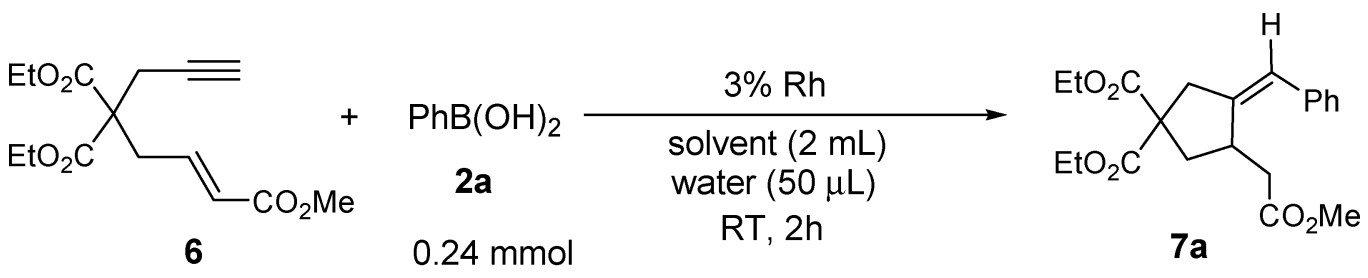

$0.2 \mathrm{mmol}$

\begin{tabular}{lllllc}
\hline Entry & Rh complex & Solvent & Time/h & ${\text { Conversion }(\%)^{a}}^{\text {Yield }^{a}(\%)^{a}}$ \\
\hline 1 & {$\left[\mathrm{Rh}(\mathrm{cod}) \mathrm{OCH}_{3}\right]_{2}$} & $\mathrm{CH}_{3} \mathrm{OH}$ & 2 & 100 & $(80)$ \\
2 & {$[\mathrm{Rh}(\mathrm{cod}) \mathrm{OH}]_{2}$} & Dioxane & 15 & 27 & 10 \\
$3^{b}$ & {$[\mathrm{Rh}(\mathrm{cod}) \mathrm{Cl}]_{2}-\mathrm{KOH}(0.3 \mathrm{eq})$} & Dioxane & 5 & 100 & 69
\end{tabular}

${ }^{a}$ Calculated by ${ }^{1} \mathrm{H}$ NMR relative to an internal standard (1,3,5-trimethoxybenzene). Isolated yields are given in parentheses. ${ }^{b} \mathrm{Contained} 6 \% \mathrm{Rh}$ and $0.2 \mathrm{~mL}$ of water and performed at $60{ }^{\circ} \mathrm{C}$.

diynes 1d and 1e, resulting in the arylation at the terminal alkyne site.

A modest yield was obtained from the reaction of a symmetric terminal 1,6-diyne (Table 5, entry 5). Both oxygen $\mathbf{1 g}$ and sulfonamide $\mathbf{1 h}$ tethered diynes can also be used as substrates (Table 5, entries 6 and 7).

The reaction of 1,7-diyne also proceeded with high chemoselectivity yielding a 6-membered cyclisation product 3ia together with a small amount of its stereoisomer with an unassigned structure in the ratio of $15: 1$ in an overall yield of $36 \%$ (Table 5, entry 8). Unfortunately, diynes $\mathbf{1} \mathbf{j}$ and $\mathbf{1 k}$, substituted with phenyl and ester groups, respectively, produced complex mixtures of various arylative cyclised products.

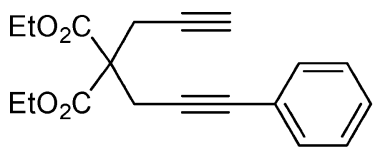

$1 \mathrm{j}$

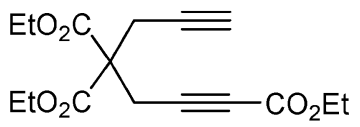

$1 \mathrm{k}$
Vinylidene formation, which is a common intermediate in various rhodium catalysis of terminal alkynes, ${ }^{7,13}$ is unlikely in our case when considering the product profile. Likewise, mindful that the reaction of diyne 1a with a phenylboronate ester 8a in dry $\mathrm{CD}_{3} \mathrm{OD}$ produced 3aa- $d_{1}$ with introduction of deuterium only at the vinylic position, which suggests the following mechanisms: coordination of organorhodium to the unsaturated carbon-carbon bonds (I) triggers vicinal addition across the unhindered terminal alkyne (II), followed by subsequent intra-carborhodation onto the next unsaturated carbon-carbon bond providing a vinyl rhodium species (IV) (Scheme 1). Alternatively, the intermediate IV may arise via oxidative cyclisation of $\mathrm{PhRh}(\mathrm{I})$ with the diyne 1a to afford a rhodacyclopentadiene intermediate (III) and following reductive elimination step. ${ }^{2 a, 14}$ Protonolysis with methanol at the last step produces product 3 and regenerates the catalytically active $\mathrm{Rh}(\mathrm{I})$ species.

An analogous reaction of monoalkyne 9 with a terminal alkyne moiety failed, however, to donate any adduct product but instead led to its full consumption giving rise to a complex mixture, ${ }^{6}$ while the corresponding internal alkyne 10 was entirely unreactive under these conditions and unchanged (Scheme 2). Comparatively, the reaction of a $1: 1$ mixture of $\mathbf{9}$ and $\mathbf{1 0}$ containing three equivalents of $\mathbf{2 a}$ in the presence of $3 \%$ rhodium yielded the same result as their corresponding individual reactions. In this last case the alkyne 9 was consumed to give a complex mixture and $\mathbf{1 0}$ was recovered unreacted. These results imply that rhodium catalysed arylation of a terminal alkyne has to be facilitated through the interaction of another intramolecular functional group with the metal centre under the established conditions.

\section{Conclusion}

We have shown in this article that unsymmetric diynes with a terminal alkyne functionality can undergo $\mathrm{Rh}(\mathrm{I})$-catalyzed arylative cyclisation in both a chemo- and stereoselective manner with organoborons to yield exocyclic diene products. The arylation took place selectively at the terminal alkyne site. The reaction worked effectively with the $\left[\mathrm{Rh}(\mathrm{cod}) \mathrm{OCH}_{3}\right]_{2}$ complex in a $\mathrm{CH}_{3} \mathrm{OH}$ solvent system at room temperature, while the $[\mathrm{Rh}(\mathrm{cod}) \mathrm{OH}]_{2}-$ dioxane system, which was reported to be a sufficient combination for analogous reactions with internal malonate-tethered diynes, ${ }^{30}$ was observed to be ineffective with diyne $\mathbf{1}$.

\section{Experimental}

\section{General}

The products were analysed by GC and GC-MS (Varian Star 3400 CX/Saturn 2000 or HP $6890 / 5973$ N) and isolated by column chromatography. High-resolution mass spectral analyses were performed at the Dortmund University of Technology Mass Spectrometry Laboratory on a Thermo Electron system. NMR spectra were recorded on a Varian VnmrJ 400 spectrometer or a Bruker DRX 400 spectrometer. Infrared spectra were obtained using Perkin-Elmer Spectrum 100 by ATR method with neat samples. Methanol was dried over $\mathrm{Mg}$ turnings and stored on molecular sieve 3A under Ar. THF, DME, and dioxane were distilled from benzophenone-ketyl under argon prior to use.

Diynes $1 \mathrm{a},{ }^{15,16} \mathbf{1 b},{ }^{15,16} 1 \mathrm{c},{ }^{15,16} 1 \mathrm{e},{ }^{17} \mathbf{1 f},{ }^{16} 1 \mathrm{~g},{ }^{18}$ and $1 \mathrm{k},{ }^{17}$ enyne $6,{ }^{3 e}$ monoalkynes 9 and $\mathbf{1 0},{ }^{3 e}$ and rhodium complexes $[\mathrm{Rh}(\operatorname{cod}) \mathrm{Cl}]_{2},{ }^{19}$ 
Table 4 Rhodium catalysed reaction of diethyl 2-(but-2-ynyl)-2-(prop-2-ynyl)malonate (1a) with various organoboronic acids (2) ${ }^{a}$

\begin{tabular}{|c|c|c|c|c|}
\hline Entry & Boronic Acid & Time/h & Product & Isolated Yield (\%) \\
\hline 1 & 13 & 1 & $\begin{array}{l}\mathrm{EtO}_{2} \\
\mathrm{EtO}_{2}\end{array}$ & 68 \\
\hline 2 & $\mathrm{H}_{3} \mathrm{C}$ & 1 & $\begin{array}{l}\mathrm{EtO}_{2} \\
\mathrm{EtO}_{2}\end{array}$ & 72 \\
\hline 3 & & 2 & $\begin{array}{l}\mathrm{EtO}_{2} \\
\mathrm{EtO}_{2}\end{array}$ & 61 \\
\hline 4 & 3 & 2 & $\begin{array}{l}\mathrm{EtO}_{2} \\
\mathrm{EtO}_{2}\end{array}$ & 72 \\
\hline 5 & & 2 & $\begin{array}{l}\mathrm{EtO}_{2} \\
\mathrm{EtO}_{2}\end{array}$ & 70 \\
\hline 6 & & 2 & $\begin{array}{l}\mathrm{EtO}_{2} \\
\mathrm{EtO}_{2}\end{array}$ & 66 \\
\hline 7 & $\mathrm{CH}_{3}$ & 4.5 & $\begin{array}{l}\mathrm{EtO}_{2} \\
\mathrm{EtO}_{2}\end{array}$ & 74 \\
\hline 8 & & 1 & $\begin{array}{l}\text { EtO } \\
\text { EtO }\end{array}$ & 74 \\
\hline 9 & $\mathrm{~B}(\mathrm{OH})$ & 2 & $\begin{array}{l}\mathrm{EtO}_{2} \\
\mathrm{EtO}_{2} \mathrm{C}\end{array}$ & 68 \\
\hline 10 & & 2 & $\begin{array}{l}\mathrm{EtO}_{2} \\
\mathrm{EtO}_{2}\end{array}$ & 80 \\
\hline
\end{tabular}


Table 5 Rhodium-catalysed reaction of diynes having a terminal alkyne terminus (1) with phenylboronic acid (2a) ${ }^{a}$

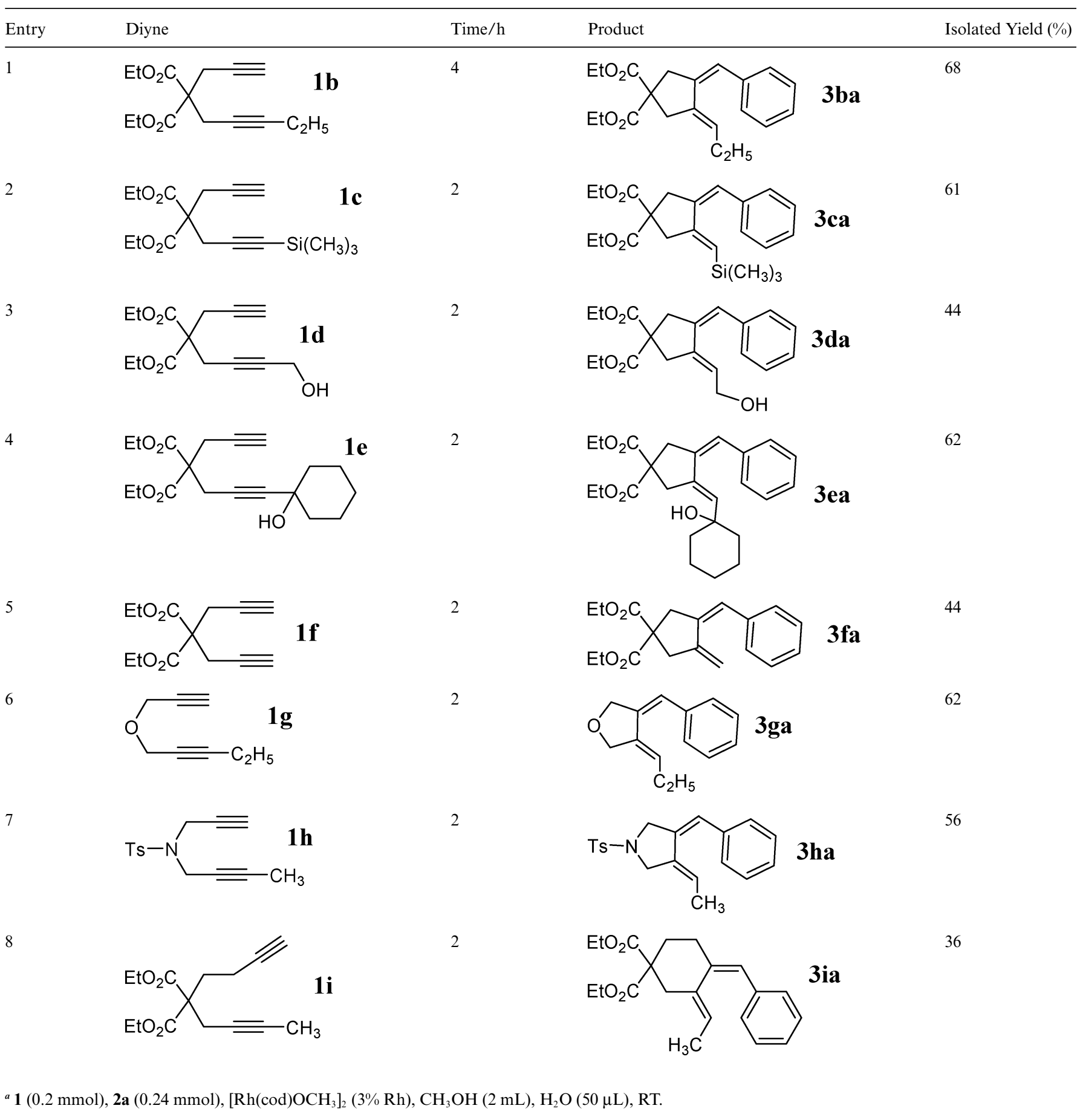

$[\mathrm{Rh}(\mathrm{cod}) \mathrm{OH}]_{2}{ }^{11}$ and $\left[\mathrm{Rh}(\mathrm{cod}) \mathrm{OCH}_{3}\right]_{2}{ }^{11}$ were synthesised based on the literature. Diyne $\mathbf{l h}$ was synthesised via deprotonation of a terminal alkyl group of $\mathrm{N}$-(prop-2-ynyl)- $N$-tosylprop-2yn-1-amine ${ }^{20}$ with BuLi and following treatment with $\mathrm{CH}_{3} \mathrm{I}$ in THF. Diyne 1i was synthesised via sequential alkylation of diethyl malonate with 4-bromo-1-butyne, ${ }^{21}$ and propargyl bromide. ${ }^{15,16}$ Diyne 1d was synthesised by the alkylation of diethyl propargylmalonate with 2-(4-chloro-but-2-ynyloxy)-tetrahydropyran and following deprotection of the hydroxyl group. ${ }^{17,22}$ Diyne $\mathbf{1 j}$ was synthesised via phenylation of diethyl propargylmalonate by the
Sonagashira coupling method followed by alkylation with 4bromo-1-butyne. ${ }^{21,23}$

\section{General procedure for the reaction of 1,6-diynes with organoboronic acids}

To a Schlenk tube was added diyne $(0.2 \mathrm{mmol})$, boronic acid (0.24 mmol), [Rh(cod)OMe $]_{2}(3 \% \mathrm{Rh})$, methanol ( $\left.2 \mathrm{~mL}\right)$, and water $(50 \mu \mathrm{L})$. The reaction mixture was stirred at room temperature under Ar until the substrate disappeared as monitored by TLC or 


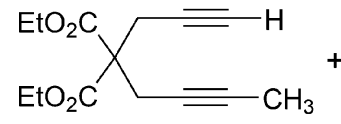

$1 \mathbf{a}$<smiles>CC1(C)COB(c2ccccc2)OC1</smiles>

$8 \mathbf{a}$
RT, $2 \mathrm{~h}$

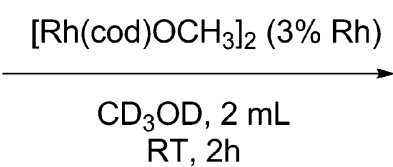

$0.2 \mathrm{mmol}$

$0.24 \mathrm{mmol}$

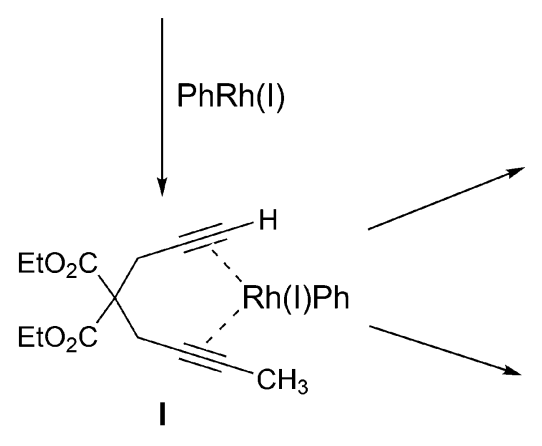

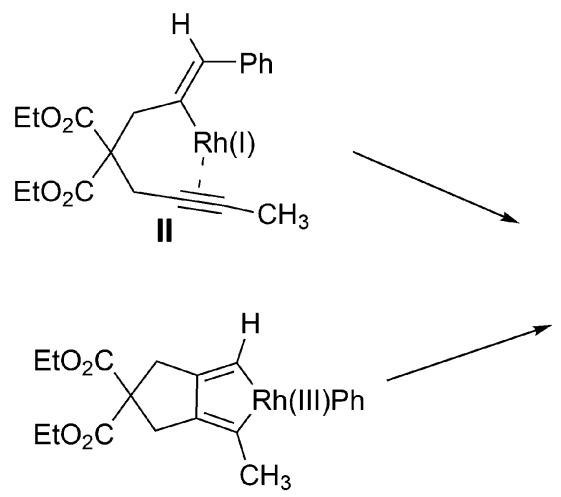

III<smiles>CCOC(=O)COc1ccccc1</smiles><smiles>COC(C)(C)C(C)(C)[18O]</smiles><smiles>CCOC(=O)C1(C(=O)OCC)CC(=C(C)[OH2+])/C(=C\c2ccccc2)C1</smiles>

Scheme 1 The arylative cyclisation reaction of 1,6-diyne 1a with phenylboronic acid ester $8 \mathbf{a}$ in $\mathrm{CD}_{3} \mathrm{OD}$ and proposed mechanisms.<smiles>C#CCC(C)(COCC)C(=O)OCC</smiles>

$0.2 \mathrm{mmol}$<smiles>CC#CCC(C)(COCC)C(=O)OCC</smiles>

2a $(0.24 \mathrm{mmol})$ $\left[\mathrm{Rh}(\mathrm{cod}) \mathrm{OCH}_{3}\right]_{2}(3 \% \mathrm{Rh})$ $\mathrm{CH}_{3} \mathrm{OH}(2 \mathrm{~mL})$ $\mathrm{H}_{2} \mathrm{O}(50 \mu \mathrm{L})$ $\mathrm{RT}, 2 \mathrm{~h}$ complete conversion no arylative product

$0.2 \mathrm{mmol}$

Scheme 2 Rhodium-catalysed reaction of diethyl 2-methyl-2-(prop-2-ynyl)malonate (9) and diethyl 2-(but-2-ynyl)-2-methylmalonate (10) with 2a

GC. The solvent was evaporated and the residue was purified by flash chromatography (hexane-EtOAc) affording the product. All the products appeared colourless or as light-yellow oil.

\section{Acknowledgements}

The support of The National Boron Research Institute (BOREN2006-14-C, 13-09), and IZTECH (2007-IYTE-14) to this work and the postdoctoral support of The Scientific and Technological Research Council of Turkey (TUBITAK) to G. Türkmen is gratefully acknowledged. We thank Ms. N. Meszaros of Dortmund University of Technology for HRMS analyses, Mrs. I. Özçelik for the measurement of NMR spectra, Dr R. Eanes for proofreading.

\section{Notes and references}

1 T. Hayashi, K. Inoue, N. Taniguchi and M. Ogasawara, J. Am. Chem. Soc., 2001, 123, 9918-9919.

2 Related reviews: (a) T. Miura and M. Murakami, Chem. Commun., 2007, 217-224; (b) S. W. Youn, Eur. J. Org. Chem., 2009, 2597-2605.

3 (a) T. Miura, M. Shimada and M. Murakami, Angew. Chem., Int. Ed., 2005, 44, 7598-7600; (b) T. Miura, Y. Takahashi and M. Murakami,
Org. Lett., 2007, 9, 5075-5077; (c) T. Miura, M. Shimada and M. Murakami, Tetrahedron, 2007, 63, 6131-6140; (d) R. Shintani, K. Okamoto, Y. Otomaru, K. Ueyama and T. Hayashi, J. Am. Chem. Soc., 2005, 127, 54-55; (e) R. Shintani, A. Tsurusaki, K. Okamoto and T. Hayashi, Angew. Chem., Int. Ed., 2005, 44, 3909-3912; (f) T. Miura, H. Nakazawa and M. Murakami, Chem. Commun., 2005, 2855-2856; (g) T. Miura, M. Shimada and M. Murakami, J. Am. Chem. Soc., 2005, 127, 1094-1095; (h) T. Miura, M. Shimada and M. Murakami, Chem.Asian J., 2006, 1, 868-877; (i) T. Miura, T. Sasaki, H. Nakazawa and M. Murakami, J. Am. Chem. Soc., 2005, 127, 1390-1391; (j) T. Matsuda, M. Makino and M. Murakami, Angew. Chem., Int. Ed., 2005, 44, 46084611; (k) T. Miura, T. Sasaki, T. Harumashi and M. Murakami, J. Am. Chem. Soc., 2006, 128, 2516-2517; (l) T. Miura, K. Ueda, Y. Takahashi and M. Murakami, Chem. Commun., 2008, 5366-5368; $(m)$ T. Miura, H. Nakazawa and M. Murakami, Chem. Commun., 2005, 2855; (n) T. Miura, H. Nakazawa and M. Murakami, Chem. Commun., 2005, 2855 2856; (o) T. Miura, M. Yamauchi and M. Murakami, Synlett, 2007, 2029-2032; ( p) R. Shintani, H. Nakatsu, K. Takatsu and T. Hayashi, Chem.-Eur. J., 2009, 15, 8692-8694.

4 T. Hayashi, M. Takahashi, Y. Takaya and M. Ogasawara, J. Am. Chem. Soc., 2002, 124, 5052-5058.

5 During the preparation of this manuscript, a Rh-catalysed reaction of a terminal alkynyl oxirane with phenylboronic acid that yields an $\alpha$ allenol structure has been reported. The rhodoarylation process seems to be facilitated by coordination of the rhodium species with the oxygen functionality of the alkyne substrate: T. Miura, M. Shimada, P. de 
Mendoza, C. Deutsch, N. Krause and M. Murakami, J. Org. Chem., 2009, 74, 6050-6054.

6 (a) M. Tabata, W. Yanc and K. Yokota, J. Polym. Sci., Part A: Polym. Chem., 1994, 32, 1113-1120; (b) M. Tabata, T. Sone and Y. Sadahiro, Macromol. Chem. Phys., 1999, 200, 265-282; (c) I. Saeed, M. Shiotsuki and T. Masuda, Macromolecules, 2006, 39, 8977-8981.

7 Y. Chen and C. Lee, J. Am. Chem. Soc., 2006, 128, 15598-15599.

8 (a) R. Itooka, Y. Iguchi and N. Miyaura, J. Org. Chem., 2003, 68, 60006004; (b) T. Hayashi, M. Takahashi, Y. Takaya and M. Ogasawara, J. Am. Chem. Soc., 2002, 124, 5052-5058.

NOE

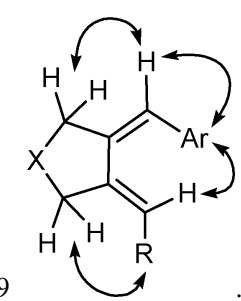

10 The 1,2-dialkylidenecycloalkanes synthesised in this study are not particularly stable molecules, decomposing in a couple of days to weeks, but can last longer if stored at deep freeze temperatures as dilute solutions under an inert atmosphere.

11 The $\left[\mathrm{Rh}(\operatorname{cod}) \mathrm{OCH}_{3}\right]_{2}$ complex can be synthesised from $[\mathrm{Rh}(\operatorname{cod}) \mathrm{Cl}]_{2}$ and $\mathrm{KOH}$ in $\mathrm{CH}_{3} \mathrm{OH}$ : R. Uson, L. A. Oro and J. A. Cabeza, Inorg. Synth., 1985, 23, 126-130.
12 S. E. Kegley, C. J. Schaverien, J. H. Freudenberger and R. G. Bergman, J. Am. Chem. Soc., 1987, 109, 6563-6565.

13 (a) Y. Fukumoto, F. Kinashi, T. Kawahara and N. Chatani, Org. Lett., 2006, 8, 4641-4643; (b) B. M. Trost and A. McClory, Angew. Chem., Int. $E d$., 2007, 46, 2074-2077; (c) A. Mizuno, H. Kusama and N. Iwasawa, Angew. Chem., Int. Ed., 2009, 48, 8318-8320.

14 H.-Y. Jang and M. J. Krische, J. Am. Chem. Soc., 2004, 126, 7875-7880.

15 T. Shimamoto, M. Chimori, H. Sogawa and K. Yamamoto, J. Am. Chem. Soc., 2005, 127, 16410-16411.

16 D. Llerena, D. Buisine, C. Aubert and M. Malacria, Tetrahedron, 1998, 54, 9373-9392.

17 B. M. Trost and M. T. Rudd, J. Am. Chem. Soc., 2005, 127, 47634776.

18 Y. Xiong, H. Xia and H. W. Moore, J. Org. Chem., 1995, 60, 64606467.

19 The proposed method involves the treatment of $\mathrm{RhCl}_{3} \cdot 3 \mathrm{H}_{2} \mathrm{O}$ with cycloocta-1,5-diene in the presence of sodium carbonate in ethanolwater mixture. However, we have performed the method in the absence of a base thus obtaining the $[\mathrm{Rh}(\mathrm{cod}) \mathrm{Cl}]_{2}$ complex in its desired yelloworange colour, otherwise, the recovered complex appeared greenish when using sodium carbonate. G. Giordano and R. H. Crabtree, Inorg. Synth., 1979, 19, 218.

20 K. Tanaka, K. Takeishi and K. Noguchi, J. Am. Chem. Soc., 2006, 128, 4586-4587.

21 R. Adams and R. M. Kamm, Organic Syntheses, 1941, Coll. Vol. 1, p.250; 1925, Vol. 4, p.11.

22 W. J. Bailey and E. Fujiwara, J. Am. Chem. Soc., 1955, 77, 165-166.

23 K. R. Roesch and R. C. Larock, J. Org. Chem., 2001, 66, 412-420. 